\title{
Ecological footprint simulation and prediction by ARIMA model-A case study in Henan Province of China
}

\author{
Jun-song Jia a , Jing-zhu Zhao a,b,* , Hong-bing Deng a, Jing Duan ${ }^{a}$ \\ a State Key Laboratory of Urban and Regional Ecology, Research Center for Eco-Environmental Sciences, Chinese Academy of Sciences, Beijing 100085, China \\ ${ }^{\mathrm{b}}$ Institute of Urban Environment, Chinese Academy of Sciences, Xiamen 361021, China
}

\section{A R T I C L E I N F O}

\section{Article history:}

Received 25 November 2008

Received in revised form 26 May 2009

Accepted 2 June 2009

\section{Keywords:}

ARIMA model

Ecological footprint

Henan Province

Simulation

Prediction

\begin{abstract}
A B S T R A C T
Ecological footprint (EF), as one of the sustainable development indicators, has received considerable attention. However, it has mostly been used as a static indicator. The accurate quantitative analysis on its development trend is still rare. Thus, the autoregressive integrated moving average (ARIMA) model was introduced to enhance the forecasting capacity of EF indicator. Taking Henan Province of China as a study area, we firstly computed the EF and the ecological carrying capacity (EC) in 1949-2006. Based on the computed results, the simulating process of the ARIMA model and the fitting and forecasting results were explained in detail. The final results demonstrated that ARIMA model could be used effectively in the simulation and prediction of EF and the predicted EF could help the decision-makers make a package of better planning for regional ecological balance or sustainable future.
\end{abstract}

(c) 2009 Elsevier Ltd. All rights reserved.

\section{Introduction}

Sustainable development has become an important goal around the world since the Rio Earth Summit (Wackernagel et al., 2004; Chen et al., 2006). So far, a variety of models, methods and indicators have been put forward to evaluate sustainable development quantitatively at regional scales. One of them, the ecological footprint (EF) indicator developed by Wackernagel and Rees (1996), has received considerable attention and been widely used (Singh et al., 2009; Li et al., 2008; Wilson et al., 2007; Cuadra and Bjorklund, 2007; Erb, 2004; Holmberg et al., 1999). EF answers a specific research question: how much of the regenerative biological capacity of the planet is demanded in a given time by a given human activity which could be the consumption of resources, the production of goods, or the supply of a service (Kitzes and Wackernagel, 2009). However, EF itself is a static indicator, which means it cannot answer another specific research question: how to accurately estimate (simulate and predict) the EF's development trend in future according to the EF's development in the past in a given place in a long time series (Yue et al., 2006) and to provide reasonable policy recommendations for regional sustainable development based on the estimated EF's

\footnotetext{
* Corresponding author at: State Key Laboratory of Urban and Regional Ecology, Research Center for Eco-Environmental Sciences, Chinese Academy of Sciences, Beijing 100085, China. Tel.: +86 10 62849112; fax: +86 1062849510 .

E-mail address: jzhao@rcees.ac.cn (J.-z. Zhao).
}

outcome in future. The focus of this paper is to answer this specific question by searching, selecting, comparing, and testing some noted data simulation and prediction methods.

Haberl et al. (2001) calculated the EF of Austria in 1926-1995 based on three different assumptive yields and described its change condition during the study period. But the regional EF's development trend in future was not discussed in Haberl's research. Senbel et al. (2003) investigated the impact factors of EF in North America and postulated several scenarios to predict regional ecological deficit (ED) in the coming century. His scenario analysis was after all a random method and had a large uncertainty. Taking the Gansu Province as an example in China, Yue et al. (2006) introduced the 'change rate' and 'scissors difference' to quantitatively analyze the development trends of EF and ecological carrying capacity (EC) during past years and to predict them in future. However, the errors of 'change rate' and 'scissors difference' would become increasingly large with the increasing amount of data. The conditions to apply Yue's method were too strict to use in some extreme situations such as some wave-like or step-like changes in time series sample data.

The traditional way of time series analysis is simple regression, which has been used since late 19th century (Ediger et al., 2006; Wei, 1994; Allen, 1997). A simple regression equation, which may be simple as linear or complex as logarithmic, inverse, quadratic, cubic, compound, power, and exponential, is really a data simulation and prediction model. These models' descriptive statistics (means and variances), goodness-of-fit $\left(R^{2}\right)$, regression equation and forecasted values may be obtained easily by 
Microsoft Office Excel database or SPSS statistical software (Ediger et al., 2006). However, as the 'change rate' and 'scissors difference' (Yue et al., 2006), the errors of these methods will also become increasingly large with the increasing amount of data.

The autoregressive integrated moving average (ARIMA) method, developed by Box and Jenkins (1976), is one of the most noted models for time series data prediction and often used in econometric research (Ediger et al., 2006; Gao, 1998). The ARIMA method has been originated from the autoregressive model (AR), the moving average model (MA) and the combination of the AR and MA, the ARMA model, which was introduced in 1926, 1937, and 1938, respectively (Ediger et al., 2006). Compared with the early AR, MA, and ARMA model, ARIMA model is more flexible in the application and more accurate in the quality of the simulative or predictive results. There are some other modified versions of ARIMA model, such as SARIMA (seasonal time series ARIMA model), CARISMA (controlled autoregressive integrated segmented moving average model), FARIMA (a method which uses the fuzzy regression method to fuzzify the parameters of the ARIMA model) and FSARIMA (a model which combines the advantages of the seasonal SARIMA model and the fuzzy regression model), etc. (Ediger et al., 2006). But, these variations are only applicable in some special cases. For general purpose, the ARIMA model is chosen in this paper to improve the simulation and prediction function of EF theory.

\section{Study area}

Henan Province, geographically ranging from $31^{\circ} 23^{\prime}$ to $36^{\circ} 22^{\prime} \mathrm{N}$ and from $110^{\circ} 21^{\prime}$ to $116^{\circ} 39^{\prime} \mathrm{E}$, is located in central China (Fig. 1). Its total land area is $1670000 \mathrm{~km}^{2}$, accounting for $1.73 \%$ of entire land area in China. Henan Province has the largest population in China and, with the population growing up, its regional resources per capita are becoming less and less. For example, the arable land area per capita is 0.087 ha in 2003, which is much lower than the national average ( 0.112 ha, Xing et al., 2005). At the same time, its economic or technical development lags behind relatively developed regions in China. Henan's ecological conditions are getting worse (Li and Fan, 2005). In particular, a lot of forests are destroyed in recent years, which leads to more serious regional soil erosion and environmental degradation. In a word, Henan plays an

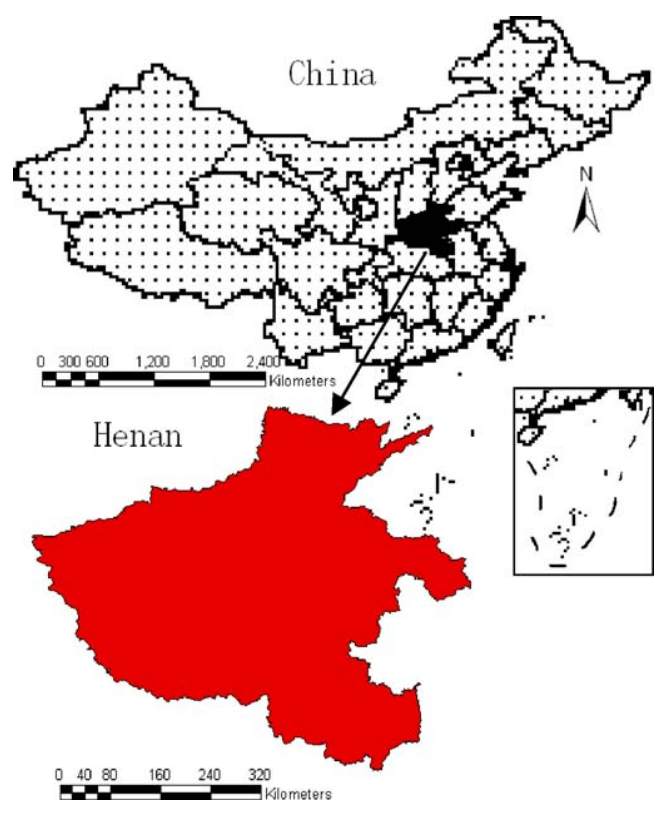

Fig. 1. The location of Henan Province in China. important and also a representative role in China. Thus, we take it as the typical case for explaining how to use the ARIMA model in the progress of EF's simulation and prediction and for elaborating the significance or effectiveness of the forecasted results in detail.

\section{Methods and data}

\subsection{EF computation}

The EF is a resource accounting tool that measures how much biologically productive land and sea is used by a given population or activity, and compares this to how much land and sea is available, using prevailing technology and resource management schemes (Rees, 1992; Wackernagel et al., 1999; Wackernagel and Rees, 1996; Kitzes and Wackernagel, 2009). Eq. (1) was used to calculate EF in Henan Province in this paper (Wackernagel et al., 1999; Wackernagel and Rees, 1996):

$\mathrm{EF}=N\left(\mathrm{EF}_{i}\right)=N \sum r_{j}\left(a a_{i}\right)=N\left[\sum r_{j}\left(\frac{C_{i}}{Y_{i}}\right)\right]$

where $\mathrm{EF}$ is the total regional $\mathrm{EF}$ (gha); $N$ is the population; $\mathrm{EF}_{i}$ is the per capita EF (gha/cap); $i$ is the consumption item number $(i=1,2, \ldots, n) ; r_{j}$ is the equivalent factor of different types of land, obtained from the literatures (Wackernagel et al., 2004); $a a_{i}$ is the ecologically productive land converted from per capita consumption of $i$ item (gha/cap); $C_{i}$ is the per capita consumption of $i$ item $(\mathrm{kg} / \mathrm{cap})$ which is decided by the productivity plus the trade balance amount (import minus export); $Y_{i}$ is the average productivity of producing $i$ item in a certain biological productive area in a certain year ( $\mathrm{kg} / \mathrm{gha})$. The per capita $\mathrm{EF}$ was divided into six types: arable land $E F(E F a)$, pasture land $E F(E F p)$, forest land $E F$ (EFfor), fossil energy land EF (EFfos), built-up land EF (EFb) and water/fishery land EF (EFw).

The EC reflects the ability of regional available land resources. Eq. (2) as used to calculate EC (Wackernagel et al., 1999; Wackernagel and Rees, 1996):

$\mathrm{EC}=N\left(\mathrm{EC}_{i}\right)=N \sum\left(a_{j} \times r_{j} \times y_{j}\right)$

where $\mathrm{EC}$ is the total regional $\mathrm{EC}$ (gha); $\mathrm{EC}_{i}$ is the per capita $\mathrm{EC}$ (gha/ cap); $a_{j}$ is the per capita biological productive area of $j$ type land in a region; and $y_{j}$ is the yield factor of different types of land, according to Wackernagel et al. (1996).

The data sources of consumption were mainly collected from Henan Province Yearbooks in 1984-2007 and Henan Statistics in 1949-1998 published by China Statistics Press. The data sources of trade balance were obtained from China Statistical Yearbooks in 1984-2007, New China's 55-Year Statistical Data in 1949-2004 and the FAO database provided by the Food and Agriculture Organization of the United Nations.

\subsection{ARIMA explication}

The basic idea of ARIMA model is: to consider the data sequence of prediction target over time as a random sequence; to use a mathematical model to approximately describe or simulate the sequence; and to predict the future values of the time series from past values and present values once this model can be identified. This ARIMA modeling approach is particularly useful when little knowledge is available or when there is no satisfactory explanatory model that relates the prediction variables to other explanatory variables (Zhang, 2003).

The equation of the ARIMA model can be expressed in different forms (Gao, 1998; Zhang, 2003; Pai and Lin, 2005). Applied in this paper is the most common one in which the future value of a variable is supposed to be a linear combination of past values and 


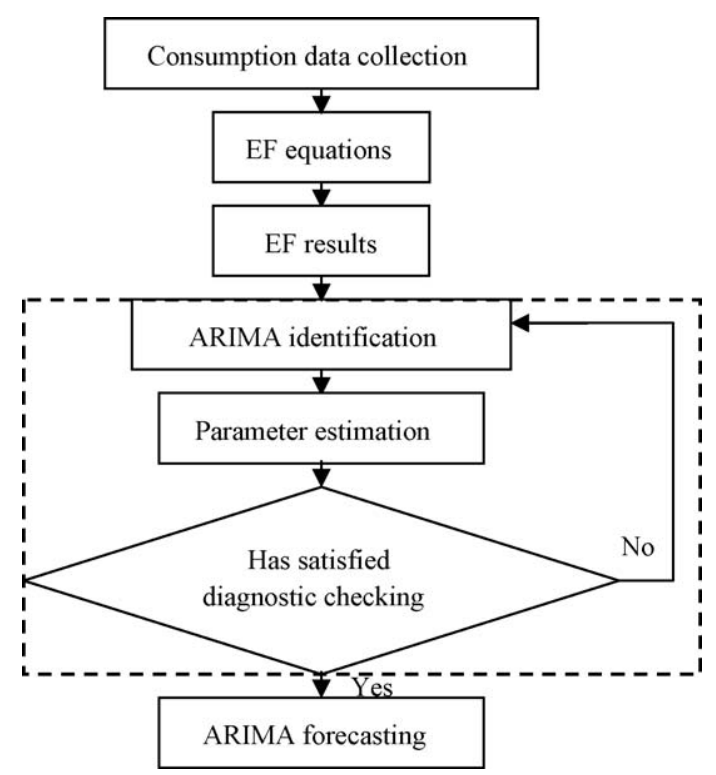

Fig. 2. Calculation flow chart of integrating EF method with ARIMA model.

past errors:

$\begin{aligned} y_{t}= & \theta_{0}+\phi_{1} y_{t-1}+\phi_{2} y_{t-2}+\cdots+\phi_{p} y_{t-p}+\varepsilon_{t}-\theta_{1} \varepsilon_{t-1} \\ & -\theta_{2} \varepsilon_{t-2}-\cdots-\theta_{q} \varepsilon_{t-q}\end{aligned}$

where $y_{t}$ is the actual value and $\varepsilon_{t}$ is the random error at time $t, \phi_{i}$ $(i=1,2, \ldots, p)$ and $\theta_{j}(j=1,2, \ldots, q)$ are the model coefficients, $p$ and $q$ are integers that are often referred to as autoregressive and moving average orders, respectively. Random errors, $\varepsilon_{t}$, are assumed to be independently and identically distributed with a mean of zero and a constant variance of $\sigma^{2}$. Eq. (3) entails several important special cases of the ARIMA family of models. If $q=0$, then (3) becomes an AR model of order $p$. When $p=0$, the model reduces to an MA model of order $q$. One central task of the ARIMA model building is to determine the appropriate model order $(p, q)$. For example, when the $p$ is determined as 1 and the $q$ is determined as 1 too, the ARIMA $(1,0,1)$ model can be easily represented as follows:

$y_{t}=\theta_{0}+\phi_{1} y_{t-1}+\varepsilon_{t}-\theta_{1} \varepsilon_{t-1}$

Fig. 2 shows the calculation flow chart of integrating EF method with ARIMA model used in this paper. First, based on the collected consumption data, the EF results of Henan Province are obtained by using the EF's computation equations (Eqs. (1) and (2)). Then, the $\mathrm{EF}$ results are considered as a random sequence and become the input to the ARIMA model. Usually, ARIMA has three phases: model identification, parameter estimation and diagnostic checking (within the dotted lines in Fig. 2).

\section{Results and discussions}

\subsection{Results of EF simulation and prediction by ARIMA model}

Taking the per capita EFa $\{X t\}$ as an example, the detailed implementation process of the ARIMA model can be elaborated as follows:

\subsubsection{Model identification}

The basic idea of model identification is that if a time series is generated from an ARIMA process, it should have some theoretical autocorrelation properties. Firstly, we should ensure that the

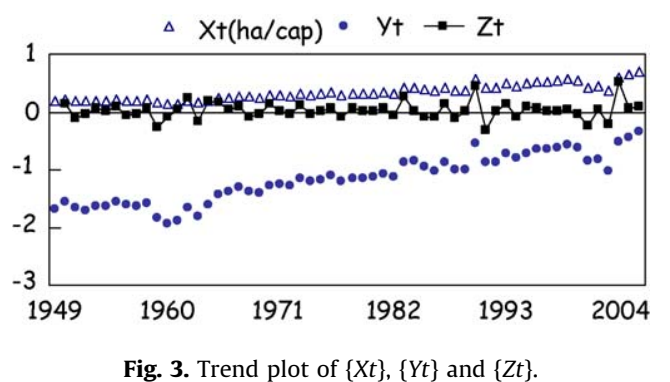

simulated data were stationary. A stationary time series has the property that its statistical characteristics such as the mean and the autocorrelation structure are constant over time. In this paper, $\{X t\}$ was increasing over time and was not stationary (Fig. 3). Therefore, we computed their logarithmic or differential function to obtain its derivative stationary time series according to Erdogdu (2007). The logarithmic series of $\{X t\}$ was $\{Y t\}$ and the 1 -order difference series of $\{Y t\}$ was $\{Z t\}$. Like $\{X t\},\{Y t\}$ still had the increase trend and, thus, was not stationarity. But $\{Z t\}$ had no increase or decrease trend, so it could be stationarity (Fig. 3). Nonstationarity can be originated from various reasons. The most important reason is the existence of the so-called unit roots. Although there exist numerous methods of unit root test, the most notable and common methods are ADF test and PP test (Erdogdu, 2007; Chi, 2007), which are used in our study. The test results showed the ADF and PP values of the time series $\{Z t\}$ were -9.995 and -9.790 which were less than the critical value of $1 \%, 5 \%$ and $10 \%$, respectively (Table 1 ). Thus the time series $\{Z t\}$ could be considered stationary according to Chi (2007). Likewise, $\{X t\}$ and $\{Y t\}$ were tested as nonstationary.

\subsubsection{Parameter estimation}

After $\{Z t\}$ was identified as stationary, we should estimate its best fit AR parameters and MA parameters according to its partial autocorrelation (PAC) function and autocorrelation (AC) function, respectively. If the $A C$ function of a stationary series died off smoothly at a geometric rate, and the PAC declined geometrically after one lag, then a first-order AR model was appropriate. Similarly, if the AC function of a stationary series died off smoothly at a geometric rate after one lag and the PAC declined geometrically, a first-order MA process would seem appropriate (Ediger et al., 2006). Fig. 4 shows the AC and PAC of $\{\mathrm{Zt}\}$. It was obvious that the AC function died off smoothly at a geometric rate after one lag and the PAC declined geometrically after two lag. Therefore, we could estimate that its AR parameter may be 2 and its MA parameter may be 1 .

However, in the practical fitting process, we could choose any other AR/MA parameters. For instance, we selected the AR

\begin{tabular}{|c|c|c|c|c|c|c|c|}
\hline \multicolumn{2}{|c|}{ Autocorrelation } & \multicolumn{2}{|c|}{ Partial Correlation } & $A C$ & PAC & Q-Stat & Prob \\
\hline & 1 & $\sqsubset$ & I & $1-0.586$ & -0.586 & 20.272 & 0.000 \\
\hline 1 & 1 & $\square$ & 1 & 20.016 & -0.499 & 20.287 & 0.000 \\
\hline । & 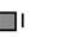 & 1 & 1 & 30.185 & -0.190 & 22.376 & 0.000 \\
\hline 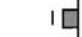 & 1 & 1 & 1 & $4-0.148$ & -0.144 & 23.736 & 0.000 \\
\hline 1 & 1 & 吅 & 1 & 50.004 & -0.177 & 23.737 & 0.000 \\
\hline 1 & I & 吅 & 1 & 60.030 & -0.221 & 23.794 & 0.001 \\
\hline 1 & 1 & 10 & 1 & 70.050 & -0.066 & 23.962 & 0.001 \\
\hline I년 & 1 & 맘 & 1 & $8-0.150$ & -0.222 & 25.492 & 0.001 \\
\hline 17 & ا & 1 & 1 & 90.205 & -0.020 & 28.397 & 0.001 \\
\hline 10 & 1 & 1 & 1 & $10-0.098$ & 0.036 & 29.069 & 0.001 \\
\hline 10 & 1 & 10 & 1 & $11-0.094$ & -0.094 & 29.705 & 0.002 \\
\hline
\end{tabular}

Fig. 4. The $A C$ and $P A C$ graph of $\{Z t\}$. 
Table 1

ADF and PP test result of $\{X t\},\{Y t\}$ and $\{Z t\}$.

\begin{tabular}{lllll}
\hline Test method & & $\{X t\}$ & $\{Y t\}$ & $\{Z t\}$ \\
\hline ADF test & $1 \%$ & -4.137 & -2.606 & -4.130 \\
& $5 \%$ & -3.495 & -1.946 & -3.492 \\
& $10 \%$ & -3.176 & -1.613 & -3.174 \\
PP test & ADF & -4.109 & -1.489 & -9.995 \\
& $1 \%$ & -2.606 & -2.606 & -2.606 \\
& $5 \%$ & -1.946 & -1.946 & -1.946 \\
& $10 \%$ & -1.613 & -1.613 & -1.613 \\
& PP & 1.435 & -1.554 & -9.790 \\
\hline
\end{tabular}

Table 2

Different ARIMA models and parameters of $\{Z t\}$.

\begin{tabular}{llcrlll}
\hline Variable & & Co-efficient & t-statistic & P-value & S.E.R. & \multicolumn{1}{l}{ SIC } \\
\hline Model 1 & C & 0.024 & 10.120 & 0.000 & 0.129 & -1.212 \\
& AR(1) & 0.486 & 3.877 & 0.000 & & \\
& MA(1) & -0.968 & -27.088 & 0.000 & & \\
Model 2 & C & 0.025 & 17.122 & 0.000 & 0.129 & -1.193 \\
& AR(1) & 0.544 & 4.067 & 0.000 & & \\
& AR(4) & -0.274 & -2.529 & 0.014 & & \\
& MA(1) & -0.997 & -17.068 & 0.000 & & \\
Model 3 & AR(1) & -0.3390 & -2.439 & 0.018 & 0.143 & -0.996 \\
& AR(2) & -0.134 & -0.960 & 0.341 & & \\
& MA(1) & -0.967 & -49.68 & 0.000 & & \\
\hline
\end{tabular}

parameters as $1,2,4,6,7,8$ and 10 . So, the question became: how did we find out and choose a model as the potential fittest model we need? The answer was to use three tests, which could indicate the significance of the parameters (models), to help us make this decision (Ediger et al., 2006). (1) $t$ statistic: the $t$ statistic was used to determine the $P$-value. For all the $P$-values, smaller value generally indicated a series of better fitting parameters. (2) The standard error of regression (S.E.R.). Similarly, smaller value generally indicated a better fitting model. (3) The Akaike Information Criterion (AIC). Model with the smallest AIC value should be choosen as the model we need in the same or similar conditions. Firstly, we should choose some best ARIMA models according to the first rule or smaller $P$-values in the fitting process (Table 2). Then we could choose the potential fittest model according to their S.E.R. or SIC values (two other rules). It could be seen that the Model 1 and Model 2 had the smallest S.E.R. values, so they might be the fittest model and the Model 3 should be excluded (Table 2). Furthermore, the Model 1 had the smaller SIC value than Model 2, so we could consider the Model 1 as the potential fittest model. Of course, we could also exclude Model 2 directly because it had a bad $P$-value $(0.014>0.001)$ according to the first rule.

\subsubsection{Diagnostic checking}

The last step of model building is the diagnostic checking. This is basically to check if the model assumptions about the errors, $\varepsilon_{t}$, are satisfied. Two diagnostic statistics or plots of the residuals can be used to examine the goodness-of-fit of the tentatively entertained model to the historical data. If the model is not adequate, a new tentative model should be identified, which is again followed by the steps of parameter estimation and diagnostic checking (Fig. 2). Only when the potential fittest models pass through the two diagnostic plots of the residuals can they be accepted as the ultimately fittest model (Zhang, 2000): (1) The reciprocals of AR and MA roots must be within the unit circle. (2) The $Q$ values of $t$ residual sequence are not obvious or their $P$ values are big enough. It could be seen that all reciprocals of AR and MA roots of the Model 1 were within the unit circle (Fig. 5) and their residual sequence $Q$ test could be adopted because their

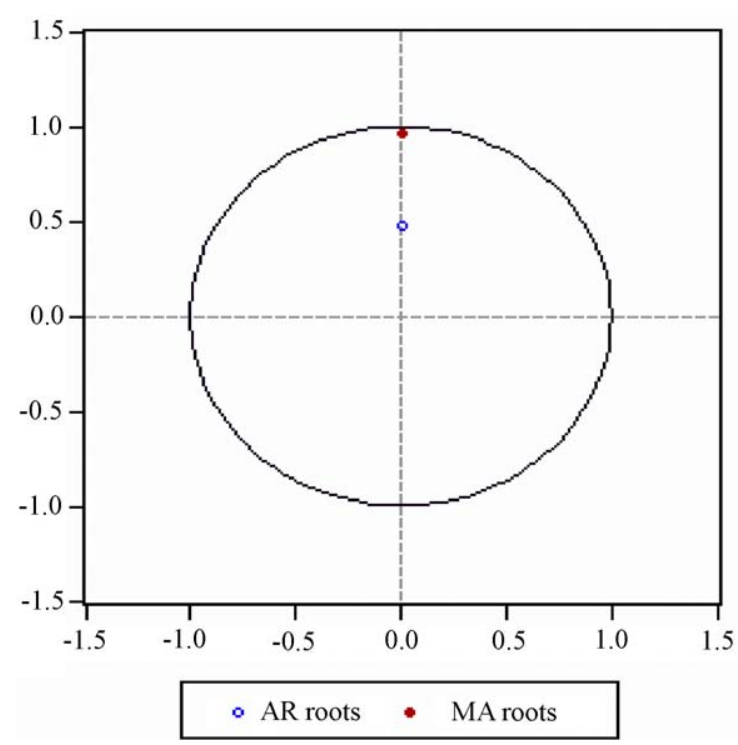

Fig. 5. Reciprocals of Model 1's roots.

$P$-values were big enough (Fig. 6). Therefore, the potential fittest Model 1 was accepted as the ultimately fittest model.

Once the ultimately fittest model was identified, the equations' form of the model could be obtained. Putting all of the parameters (coefficients) of Model 1 (Table 2) into Eq. (3), we could obtain firstly the equation of series $\{Z t\}$ :

$Z_{t}=0.012+0.486 Z_{t-1}+a_{t}+0.968 a_{t-1}$

The series $\{Z t\}$ was the 1 -order difference of $\{Y t\}$, so $\{Y t\}$ could be expressed as:

$Y_{t}=Y_{t-1}+0.012+0.486 Z_{t-1}+a_{t}+0.968 a_{t-1}$

The series $\{Y t\}$ was the logarithmic function of $\{X t\}$, so $\{X t\}$ could be expressed as:

$X_{t}=e^{Y_{t-1}+0.012+0.486 Z_{t-1}+a_{t}+0.968 a_{t-1}}$

Above formula could be considered as the final equation of the per capita EFa model. In the same way, we could obtain the fittest models and their equations of any other $E F(E C)$. Some fitting effect graphs and predictive effect graphs of EF and EC to be mentioned in Section 4.2 were showed in Fig. 7. For saving space, the simulation equations of any other EF or EC were omitted.

It should be explained that the EFa had a increasing amount ( 0.515 gha/cap) from 0.187 gha/cap in 1949 to 0.702 gha/cap in 2006 and its average annual increasing percentage was about 2.3 (Fig. 7a). Similarly, the EFfos had a increasing amount (1.147 gha/ cap) from 0.004 gha/cap in 1949-1.151 gha/cap in 2006 and its

\begin{tabular}{|c|c|c|c|c|c|}
\hline Autocorrelation & Partial Correlation & $A C$ & PAC & Q-Stat & Prob \\
\hline । & 1 & $1-0.040$ & -0.040 & 0.0924 & \\
\hline 1 & 1 & 20.047 & 0.046 & 0.2279 & \\
\hline 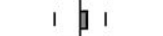 & 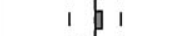 & 30.074 & 0.078 & 0.5670 & 0.451 \\
\hline 1밈 & 梠 । & $4-0.169$ & -0.167 & 2.3474 & 0.309 \\
\hline 可 । & 1든 & $5-0.137$ & -0.162 & 3.5485 & 0.315 \\
\hline 17 & 11 & $6-0.036$ & -0.039 & 3.6329 & 0.458 \\
\hline 1 & 1 & $7-0.021$ & 0.020 & 3.6615 & 0.599 \\
\hline 1 पे & I만 & $8-0.131$ & -0.140 & 4.8151 & 0.568 \\
\hline 1 & 171 & 90.128 & 0.073 & 5.9405 & 0.547 \\
\hline $1 \sqrt{1}$ & 1 [ 1 & $10-0.056$ & -0.069 & 6.1595 & 0.629 \\
\hline 10 & 1 다 1 & $11-0.073$ & -0.091 & 6.5414 & 0.685 \\
\hline
\end{tabular}

Fig. 6. Residual sequence $Q$ test of Model 1. 


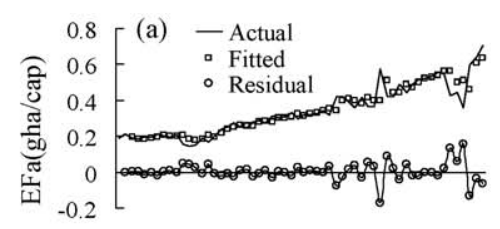

$\begin{array}{llllll}1949 & 1960 & 1971 & 1982 & 1993 & 2004\end{array}$

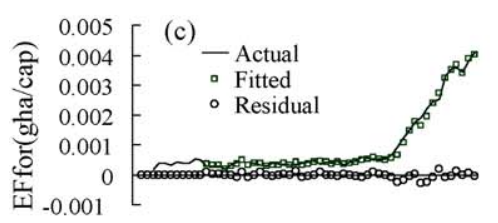

$\begin{array}{llllll}1949 & 1960 & 1971 & 1982 & 1993 & 2004\end{array}$

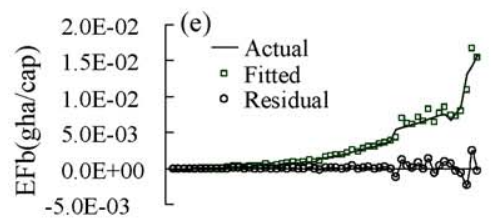

194919601971198219932004
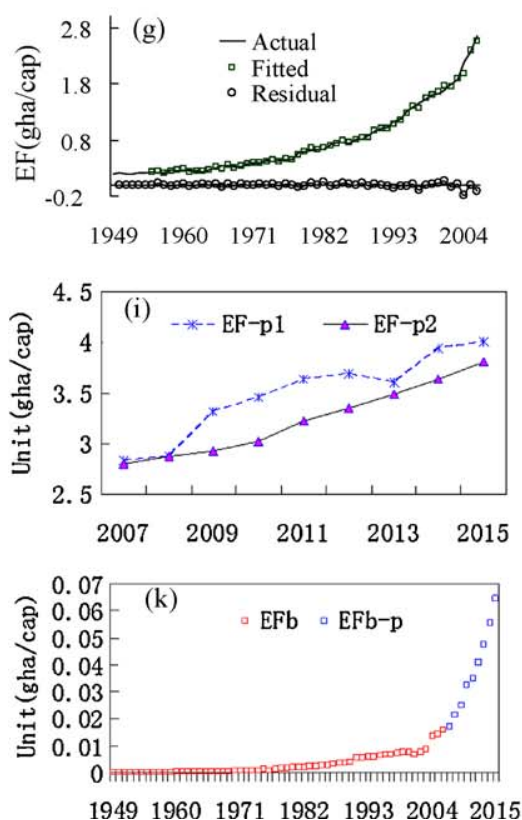
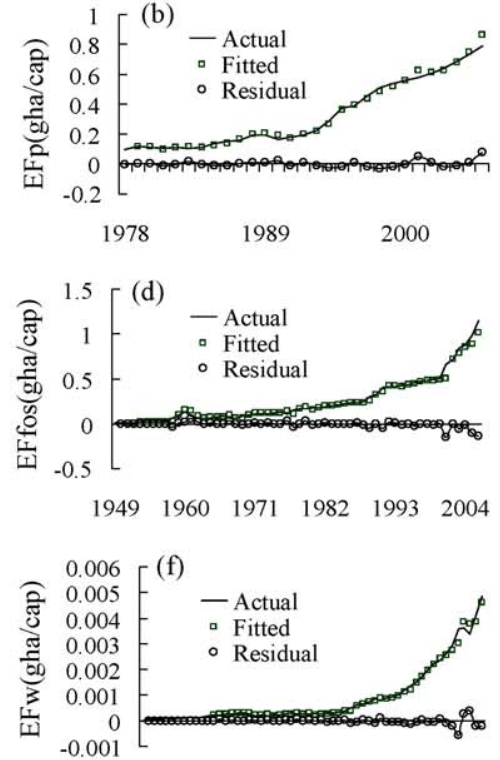

$194919601971 \quad 1982 \quad 1993 \quad 2004$
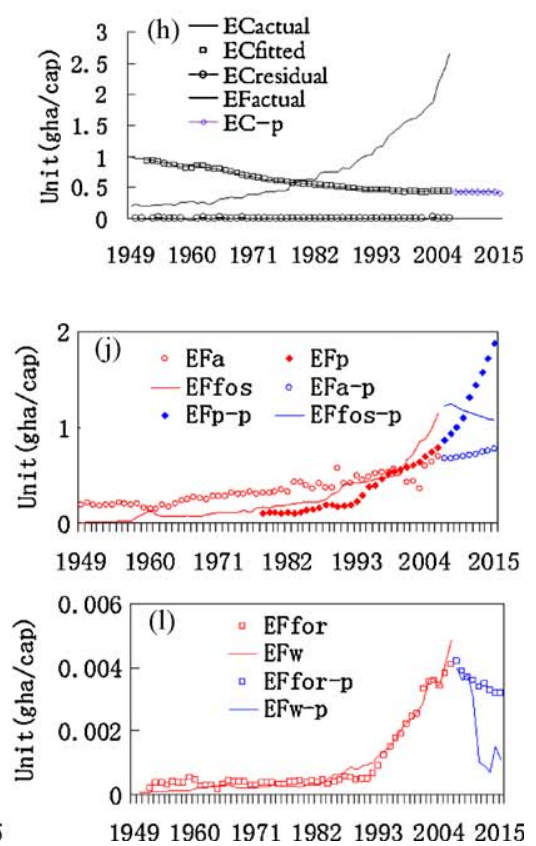

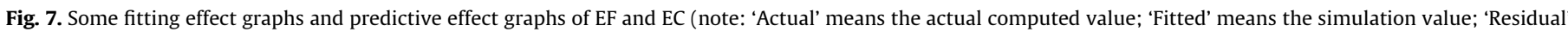

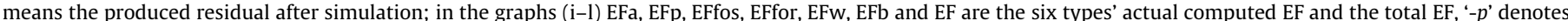

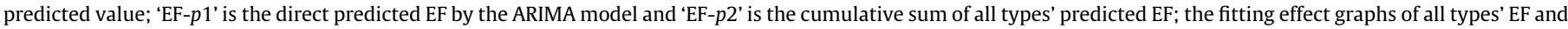

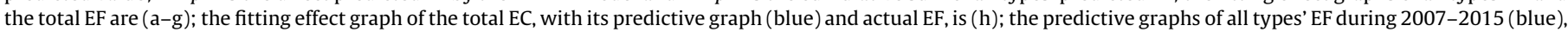

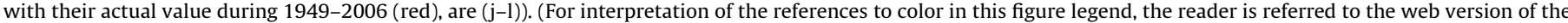
article.)

average annual increasing percentage was about 10.1 (Fig. 7d). The $\mathrm{EFb}$ had a increasing amount (0.016 gha/cap) from 1E-06 gha/cap in 1949-0.016 gha/cap in 2006 and its average annual increasing percentage was about 18.1(Fig. 7e).

For the EFp (Fig. 7b), we could only obtain its computed values from 1978 (0.098 gha/cap) to 2006 (0.786 gha/cap) because the corresponding original data from 1949 to 1977 were unavailable. Its increasing amount was 0.689 gha/cap and average annual increasing percentage was about 7.5. Similarly, we also lacked the corresponding original data for EFfor from 1949 to 1951 (Fig. 7c) and for EFw in 1949 (Fig. 7f). For the EFfor, its increasing amount was about 0.004 gha/cap from 1952 (2E-04 gha/cap) to 2006 ( 0.004 gha/cap) and average annual increasing percentage was about 5.6. For the EFw, its increasing amount was about 0.005 gha/ cap from 1950 (5.4E-05 gha/cap) to 2006 (0.005 gha/cap) and average annual increasing percentage was about 8.2.

Besides, the computed values of total EF and EC were showed in Fig. $7 \mathrm{~g}$ and $\mathrm{h}$ and the predictive values of total EF, EC and different types' EF (blue) were showed in Fig. 7h-l. All of them were further discussed in the following Section.

\subsection{Discussion}

4.2.1. Significance of EF's simulation and prediction by ARIMA model

Overall, all type's EF and the total EF (Fig. 7a-h) had an increase trend while the total EC (Fig. 7h) had a decrease trend during 
1949-2006. At first, the total EF was always smaller than the total $\mathrm{EC}$, which meant the ecological deficit (ED, total EC minus total EF) of the Henan region was positive. In another word, there was an ecological surplus (ES). The total EF exceeded the total EC at about 1978 and thereafter (Fig. 7h), which meant Henan Province had the negative ED or the carrying capacity of its natural resources was not enough to support regional human activities. Based on their predicted results (Fig. $7 \mathrm{~h}$ and $\mathrm{i}$ ), the total EF still had a increase trend and the EC had a decrease trend. Thus, the regional ED was increasing and the ecological imbalance situation of Henan Province was worse and worse.

Secondly, as was showed in Fig. 7, the EFfor, EFb and EFw took negligible shares in the total per capita EF $(0.005,2.0 \mathrm{E}-02$ and $0.006 \ll 2.8$, in Fig. 7 c, e, f, g, respectively) and the EFa, EFp, EFfos were the main components of the total per capita $\operatorname{EF}(0.8,1.0$, $1.5 \approx 2.8$, in Fig. 7 a, b, d, respectively), which meant people's living demand for rice, grain, meat and fossil-energy-food were the main sources to support life. However, based on the predicted results of ARIMA model, we should also pay more attention to the EFb because it had an obviously growth rate in the predicted 20072015 years (Fig. 7k), which meant the area used for construction, such as housing and road, would increase very rapidly. This was consistent with the fact that more and more people would possibly migrate into the cities.

Furthermore, the EFp would increase with an obvious growth rate and the EFa would have a steady but slow growth during 2007-2015 from Fig. 7j, which showed people's demand for meat food (not grains) would increase rapidly and people's diet structure would mainly rely on meat. This would rapidly increase regional EF and enlarge the ED.

Unexpectedly, the EFfos would reach its peak in 2008 and decrease gradually during 2009-2015, which might result from the increasing emphasis of energy saving and the implementation of new technology and management methods in energy conservation. Similarly, the EFfor had a slow decrease. The EFw had a quick decrease and some vibrations. The specific reasons of these trends might come from the errors of data or EF model itself.

So, based on the results above, the local governments could make suitable strategic planning for regional ecological balance and sustainability development. For example, it should be encouraged that people should have a healthy lifestyle with more fruits and vegetables and less meat, so as to slow down the growing consumption of pasture resources. In addition, people should increase land productivity through technological innovations, so as to enhance the total regional EC or decrease regional ED etc.

In a word, from the ecological point of view, the integrated use of the ARIMA model and the EF could facilitate the discussions on the ecological situation in long time series and make the results of EF more reliable or less controversial. Thus, the local decisionmaker could make more suitable strategic planning for regional ecological balance or sustainable future.

\subsubsection{Potential error sources}

A perfect modeling and prediction procedure does not exist. Potential errors might come from various sources. (1) The inaccurate initial data itself for computating EF. (2) The inherent flaws of EF. For example, the global average yields (GAY) were an average value of agricultural outputs of different countries and regions in a certain year (Yue et al., 2006). So, for Henan Province, the annual GAY should be used to compute EF. But in reality, we used only one year's GAY in this paper because of the lack of data. (3) Other sources. This data-trend extrapolation method (ARIMA model itself) had the assumption that any other factors (e.g. population, affluence and technology) had influenced EF in the past would continue to bring the same influence in the future. But actually, they might change with time and other different situations.

\section{Conclusions}

ARIMA model could be used effectively in the simulation and prediction of EF. Although the predicted EFs had errors resulting from some possible reasons, they could still be used as a reference and help the decision-makers make a package of better planning for regional ecological balance or sustainable future.

\section{Acknowledgements}

This work was financially supported by 100 Talents Programme of The Chinese Academy of Sciences: comprehensive study on sustainable urban construction. The authors would like to thank Dr. B.F. Zheng for helping collect food and energy consumption data, to thank Dr. W.C. Wu, senior product specialist at ERDAS (Greater Atlanta Area) for her careful proofreading and revision of the English Language, and to thank the anonymous reviewers and the editors for their useful comments on earlier versions of this paper.

\section{Appendix A. Supplementary data}

Supplementary data associated with this article can be found, in the online version, at doi:10.1016/j.ecolind.2009.06.007.

\section{References}

Allen, M.P., 1997. Understanding Regression Analysis. Plenum Press, New York and London.

Box, G.E.P., Jenkins, G.M., 1976. Time Series Analysis: Forecasting and Control, revised ed. Holden-Day, San Francisco, USA.

Chen, M., Wang, R.S., Zhang, L.J., Xu, C.G., 2006. Temporal and spatial assessment of natural resource use in China using ecological footprint method. International Journal of Sustainable Development and World Ecology 13 (4), 255-268.

Chi, Q.S., 2007. Forecasting the increase of petroleum consumption in China based on the ARIMA model. Resources Sciences 29 (5), 69-73 (in Chinese).

Cuadra, M., Bjorklund, J., 2007. Assessment of economic and ecological carrying capacity of agricultural crops in Nicaragua. Ecological Indicators 7 (1), 133-149.

Ediger, V.S., Akar, S., Ugurlu, B., 2006. Forecasting production of fossil fuel sources in Turkey using a comparative regression and ARIMA model. Energy Policy 34 (18), 3836-3846.

Erb, K.-H., 2004. Actual land demand of Austria 1926-2000: a variation on ecological footprint assessments. Land Use Policy 21 (3), 247-259.

Erdogdu, E., 2007. Electricity demand analysis using cointegration and ARIMA modelling: a case study of Turkey. Energy Policy 35 (2), 1129-1146.

Gao, H.X., 1998. SAS System: SAS/ETS Software Manual. China Statistics Press, Beijing, China (in Chinese).

Haberl, H., Erb, K.-H., Krausmann, F., 2001. How to calculate and interpret ecological footprints for long periods of time: the case of Austria 1926-1995. Ecological Economics 38 (1), 25-45.

Holmberg, J., Lundqvist, U., Robèrt, K.-H., Wackernagel, M., 1999. The ecological footprint from a systems perspective of sustainability. International Journal of Sustainable Development and World Ecology 6 (1), 17-33.

Kitzes, J., Wackernagel, M., 2009. Answers to common questions in ecological footprint accounting. Ecological Indicators 9 (4), 812-817.

Li, G.J., Wang, Q., Gu, X.W., Liu, J.X., Ding, Y., Liang, G.Y., 2008. Application of the componential method for ecological footprint calculation of a Chinese university campus. Ecological Indicators 8 (1), 75-78.

Li, J., Fan, Y., 2005. Problems and countermeasures of farmland quality in Henan Province. Areal Research and Development 24 (2), 88-91 (in Chinese).

Pai, P.F., Lin, C.S., 2005. A hybrid ARIMA and support vector machines model in stock price forecasting. Omega 33 (6), 497-505.

Rees, W.E., 1992. Ecological footprints and appropriated carrying capacity: what urban economics leaves out. Environment \& Urbanization 4 (2), 121-130.

Senbel, M., McDaniels, T., Dowlatabadi, H., 2003. The ecological footprint: a nonmonetary metric of human consumption applied to North America. Global Environmental Change 13 (2), 83-100.

Singh, R.K., Murty, H.R., Gupta, S.K., Dikshit, A.K., 2009. An overview of sustainability assessment methodologies. Ecological Indicators 9 (2), 189-212.

Wackernagel, M., Monfreda, C., Schulz, N.B., Erb, K.-H., Haberl, H., Krausmann, F., 2004. Calculating national and global ecological footprint time series: resolving conceptual challenges. Land Use Policy 21 (3), 271-278. 
Wackernagel, M., Onisto, L., Bello, P., Linares, A.C., 1999. National natural capital accounting with the ecological footprint concept. Ecological Economics 29 (3), 375-390.

Wackernagel, M., Rees, W.E., 1996. Our Ecological Footprint: Reducing Human Impact on the Earth. New Society Publishers, Gabriola Island, Philadelphia, USA.

Wei, W.W.S., 1994. Time Series Analysis. Addison-Wesley Publishing Inc., USA and Canada.

Wilson, J., Tyedmers, P., Pelot, R., 2007. Contrasting and comparing sustainable development indicator metrics. Ecological Indicators 7 (2), 299-314.
Xing, X., Wu, K., Lu, Q., Zhang, J., 2005. Studies on changes and the driving forces of cultivated land in Henan Province. Journal of Henan Agricultural Sciences 33 (12), 56-61 (in Chinese).

Yue, D., Xu, X., Li, Z., Hui, C., Li, W., Yang, H., Ge, J., 2006. Spatiotemporal analysis of ecological footprint and biological capacity of Gansu China 1991-2015: down from the environmental cliff. Ecological Economics 58 (2), 393-406.

Zhang, G.P., 2003. Time series forecasting using a hybrid ARIMA and neural network model. Neurocomputing 50 (1), 158-175.

Zhang, X.T., 2000. Econometric Analysis, first edition. Economic Science Press, Beijing, China (in Chinese). 